\title{
Epidemiological and Evolutionary Profile of HIV-HBV Co-Infected Patients Followed at Ambulatory Treatment Center in Fann Hospital Dakar-Senegal
}

\author{
Ndeye Fatou Ngom-Gueye ${ }^{1,2,3}$, Mahamat Ali Bolti ${ }^{3}$, Abdoul Aziz Ndiaye ${ }^{2}$, Kine Ndiaye ${ }^{1}$, Makhtar Ndiaga Diop ${ }^{1}$, \\ Coumba Touré-Kane ${ }^{4}$, Halimatou Diop-Ndiaye ${ }^{4}$, Cheikh Tidiane Ndour ${ }^{3}$, Moussa Seydi ${ }^{3} \&$ Mame Awa Faye $^{3}$ \\ ${ }^{1}$ Ambulatory Treatment Center, Fann University Teaching Hospital, Dakar, Senegal \\ ${ }^{2}$ Department of Community Health, Alioune Diop University, Bambey, Senegal \\ ${ }^{3}$ Department of Infectious Diseases, Fann University Teaching Hospital, Dakar, Senegal \\ ${ }^{4}$ Virology and Bacteriology laboratory, Aristide Le Dantec Teaching Hospital, Dakar, Senegal \\ Correspondence: Ndeye Fatou Ngom-Gueye, University Alioune DIOP, Bambey, Senegal. Tel: 221776306093. \\ E-mail: ndeyetouti98@gmail.com
}

Received: December 27, 2016 Accepted: January 20, 2017 Online Published: March 27, 2017

doi:10.5539/gjhs.v9n4p190 URL: https://doi.org/10.5539/gjhs.v9n4p190

\begin{abstract}
Context: Human immunodeficiency virus (HIV) and Hepatitis B virus (HBV) infections are major global public health problems because of their frequency, complications and probable socio-demographic consequences.

Viral hepatitis B is identified as more frequent cause of morbidity and mortality in people living with HIV.

The objective of this study was to describe the epidemiological and evolutionary profile of HIV-HBV co-infected patients, treated at CTA/CHNU Fann, in Dakar, Senegal.
\end{abstract}

Methodology: This is a retrospective, descriptive and analytical study of patients aged at least 18 years, co-infected with HIV-HBV and followed-up at CTA under ART for at least one year from January 2010 to December 2014.

Results: The study included 457 patients. 58 of these patients were diagnosed positive, (12.7\%) of HIV-HBV prevalence. The average age of patients was $39.62 \pm 10.12$ years with extremes ranging from 21 to 61 years. The sex ratio was 1.23. (96\%) of patients were infected with HIV-1 and those at WHO stages III and IV were (67\%). The average CD4 count at baseline was 235 cells $/ \mathrm{mm}^{3}$ [3-936]. Plasma HIV viral load average at baseline was 4.1 $\log$ copies/ml [3.89-5.12] copies/ml. The average body mass index (BMI) was $21.42 \pm 3.82 \mathrm{Kg} / \mathrm{m}^{2}$. Fever and degraded general status were respectively $(65 \%)$ and $(60 \%)$ followed by hepatomegaly and jaundice. The lethality was $3.45 \%$. Of the 58 patients co-infected with HIV-HBV, 51/58 (87.93\%) were under a therapeutic regimen containing Tenofovir/lamivudine or Tenofovir/Emtricitabine and 7 patients under a regimen containing lamivudine. At 48 weeks of treatment a good evolution of the biological parameters was noted: (90\%) had a controlled viral load, (91\%) a normal transaminase, (79\%) a normal serum creatinine. Only 29\% had a CD4 cell count $<350$ cells $/ \mathrm{mm}^{3}$.

Conclusion: The Seroprevalence of viral hepatitis B remains relatively high (12.70\%) among PLHIV in Dakar. While active search for hepatitis B has been effective in all PLHIV since 2010, overall management remains a challenge as hepatitis B markers and viral DNA assay are not at the reach of patients.

Keywords: HIV/HBV co-infection, Seroprevalence

\section{Introduction}

Human immunodeficiency virus and hepatitis B virus (HIV/HBV) co-infection is common due to similar methods of transmission.

HBV infection in people living with human immunodeficiency virus (PLHIV) in sub-Saharan Africa is characterized by high prevalence, vertical and horizontal transmission, late diagnosis, and severe prognosis due to late diagnosis (Attia et al., 2012). In addition, the incidence of ARV-related hepatotoxicity increases with co-infection. 
The prevalence of co-infection with hepatitis B virus (HBV) is high in the population of PLVIH. This is observed in 5 to $15 \%$ of patients infected with the human immunodeficiency virus (HIV) in the world (OMS, 2013). However, few epidemiological data are available on this co-infection (Thio et al., 2013).

In Africa, the prevalence of co-infection ranges from 20 to 30\% (Attia, 2007). Vertical and perinatal transmissions are the most frequent routes, including sexual and blood transmissions.

The prevalence of occult HBV infections is underestimated (Raimondo, Caccamo, Filomia, \& Pollicino, 2013). In PLHIV, the proportion of occult replication can reach $40 \%$. This rate is estimated at $2 \%$ in mono-infected patients with HBV. It varies from 0 to $89.5 \%$ depending on the area concerned (Mehdi, Sakineh, Mohammad, Mansour, \& Alireza, 2012). This occult infection is more common in PLHIV and those co-infected with HCV (Mehdi, 2013). In Senegal, studies conducted in 2008 showed $16.8 \%$ of HBV seroprevalence in PLHIV with a similar prevalence for HBV in the general population (17\%) (Diop-Ndiaye et al., 2008). A study conducted at the same site in 2012 found $11 \%$ of prevalence of HBV in pregnant women (Lô et al., 2012).

HIV infection alters the natural history of HBV infection and aggravates the overall prognosis of chronic hepatitis B (Joshi, O'Grady, Dieterich, Gazzard, \& Agarwal, 2011). The appearance of active pharmaceutical drugs on both HIV and HBV such as Tenofovir (TDF), Lamivudine (3TC), and Emtricitabine (FTC) have improved the survival of patients co-infected with the two HIV viruses (James, Lai, Seta, \& Yuen, 2011). HAART should be initiated as soon as possible in all HBV-co-infected patients, regardless of CD4 T-cell count. Treatment should include pharmaceutical drugs with dual anti-HIV and anti-HBV activity (OMS, 2013, Miailhes et al., 2013).

The general objective of this work is therefore to determine the epidemiological, clinical, biological and evolutionary profile of patients co-infected with HIV-HBV followed at the CTA/Fann Hospital in Dakar, Senegal.

\section{Method}

This is a retrospective descriptive study. Patient selection was based on the database of Fann CTA/CHNU.

All patients aged at least 18 years, co-infected with HIV-HBV followed-up at CTA, on ART for at least one year from January 2010 to December 2014 were included in this study.

All patients under the age of 18 , as well as those in specific research programs, were excluded from the study.

Data extraction was performed using ESOPE database on Microsoft Excel 2003, and data analysis was done using EPI-INFO version 6 software. A total of 58 patients were included.

Statistical parameters used in the analysis of the data were: frequency, proportion (with confidence interval), arithmetic average (with confidence interval), and standard deviation. We used hypothesis tests to compare the different statistical parameters. T-Student test was used to compare the different averages and the Chi-square test to compare the different proportions per group. The threshold of $\mathbf{p}=\mathbf{0 . 0 5}$ was considered significant.

\section{Ethical Aspects}

An anonymous database was compiled from medical and social records of patients at Ambulatory Treatment Center (CTA-). No information revealing the identity of the patients was included in this study. The database remains a CTA property. The study received prior approval by the head of the Clinic of Infectious Diseases.

\section{Results}

\subsection{Epidemiological and Socio-Demographic Characteristics of the Population Studied at Inclusion}

Of the 457 viral hepatitis B screening performed in PLHIV from 1 January 2010 to 31 December 2014, 58 were positive. This represents an HIV-HBV co-infection prevalence of $12.7 \%$. Of the 58 co-infected patients, 11 were screened in 2010, 12 in 2011, 18 in 2012, 9 in 2013 and 8 in 2014.

The average age of patients was $39.62 \pm 10.12$ years with extremes ranging from 21 to 61 years. Our sample consisted of 32 men for 26 women with a sex ratio of 1.23 . The average body mass index (BMI) was $21.42 \pm 3.82$ $\mathrm{Kg} / \mathrm{m}^{2}$ with extremes of $14.9 \mathrm{Kg} / \mathrm{m}^{2}$ and $32.77 \mathrm{Kg} / \mathrm{m}^{2}$. Patients were infected with $\mathrm{HIV}-1$ in $96.55 \%$ of cases.

The median CD4 T lymphocyte at inclusion was 235 cells $/ \mathrm{mm}^{3}$ [3-936]. The median plasma HIV viral load at inclusion was $4.1 \log$ copies $/ \mathrm{ml}$ [3.89-5.12] copies $/ \mathrm{ml}$. The average transaminase (ALT) was $27.22 \pm 25.11 \mathrm{UI} / \mathrm{l}$ at inclusion. The average creatinine levels were $10.32 \pm 3.05 \mathrm{mg} / \mathrm{l}$. The average of plates was $240189.70 \pm$ $93899.06 / \mathrm{mm}^{3}$ with extremes of 25000 and $457000 / \mathrm{mm} 3$. (Table 1) 
Table 1. Socio-demographic, clinical and biological characteristics of 58 patients co-infected with HIV-HBV at inclusion

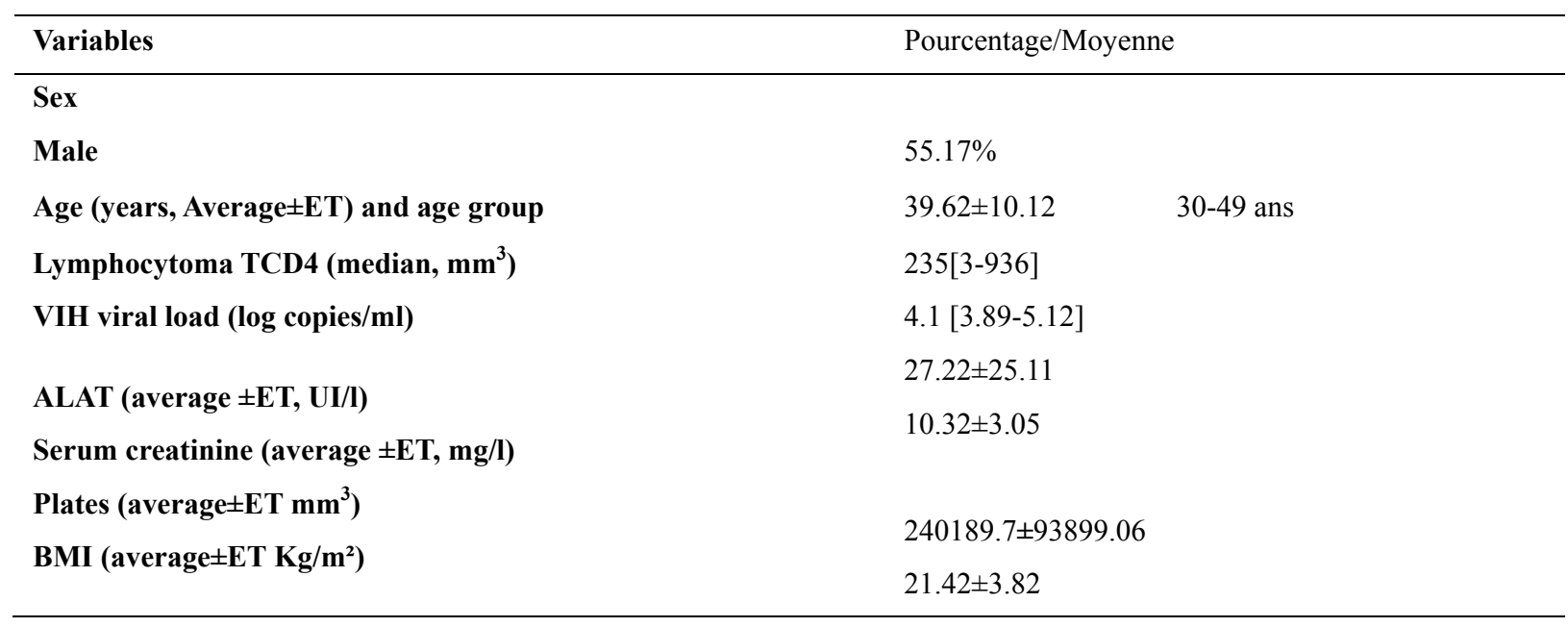

Fever and degraded general status were the most frequent signs (65.52\%) and (60.34\%), respectively, followed by hepatomegaly and jaundice.

More than half of patients were at stages III and IV as per the WHO staging system, respectively $(37.93 \%$ and $29.31 \%$ ) (Table 2).

Table 2. Distribution of Patients according to the WHO Clinical Staging system ( $\mathrm{N}=58)$

\begin{tabular}{ll}
\hline WHO Staging & Percentage (\%) \\
\hline Stage 1 & 17.24 \\
Stage 2 & 29.31 \\
Stage 3 & 37.93 \\
Stage 4 & 15.52 \\
\hline
\end{tabular}

We noted that (32.04\%) were smokers and $12 / 58(20.69 \%)$ ethyl. Four patients were using hard drug $(6.90 \%)$ and $30 / 58(51.72 \%)$ had already developed an opportunistic disease during their progression to antiretroviral therapy (Table 3).

Table 3. Distribution of patients according to their lifestyle and ATCDS IOs

\begin{tabular}{lll}
\hline & $\mathrm{n}$ & $\%$ \\
\hline Alcohol & 12 & 20.69 \\
Tobacco & 18 & 32.04 \\
Drug & 4 & 6.90 \\
Opportunistic affections & 30 & 51.72 \\
\hline
\end{tabular}

\subsection{Patient Treatment Regimen}

Of the 58 patients co-infected with HIV-HBV, 51/58 (87.93\%) were under a treatment regimen containing Tenofovir/lamivudine or Tenofovir/Emtricitabine and 7 patients under the lamivudine regimen (Table 4). 
Table 4. Distribution of patients according to their treatment regimen $(\mathrm{N}=58)$

\begin{tabular}{ll}
\hline Therapeutic regimen & Percentage (\%) \\
\hline TDF+3TC/FTC+NVP/EFV & $\mathbf{7 9 . 3 1}$ \\
TDF+3TC/FTC+LPV/rt & 8.62 \\
$\mathrm{AZT} / \mathrm{ABC}+3 \mathrm{TC}+\mathrm{LP} / \mathrm{rt}$ & 8.62 \\
$\mathrm{AZT}+3 \mathrm{TC}+\mathrm{EFV}$ & 3.45 \\
\hline
\end{tabular}

\subsection{Evolution}

At inclusion, (65\%) had severe immunosuppression with $\mathrm{CD} 4<350$ cells $/ \mathrm{mm}^{3}$, whereas after 48 weeks of treatment, only 17/58 (29.12\%) were severely immunosuppressed. At 24 weeks of antiretroviral therapy, (86.21\%) patients had undetectable HIV plasma viral load and (90\%) after 48 weeks. Transaminases were normal in (84.48\%), after 48 weeks of treatment, (91.38\%) had normal transaminase levels.

Serum creatinine levels were high $(\geq 13 \mathrm{mg} / \mathrm{l})$ in $(60.34 \%)$ at inclusion and 12/58 (20.6\%) after 48 weeks of ARV therapy $(\mathrm{p}=0.43)($ Table 5$)$.

Table 5. Distribution of patients according to changes in biological parameters at J0; 24 weeks and 48 weeks of antiretroviral therapy

\begin{tabular}{|c|c|c|c|c|c|c|c|c|}
\hline \multirow{2}{*}{ Biological Parameters } & & \multicolumn{2}{|l|}{ J0 } & \multicolumn{2}{|c|}{ M6 (S24) } & \multicolumn{2}{|c|}{ M12 (S48) } & \multirow{2}{*}{ p-value } \\
\hline & & $\mathrm{N}$ & $\%$ & $\mathrm{~N}$ & $\%$ & $\mathrm{~N}$ & $\%$ & \\
\hline \multirow{2}{*}{ TCD4 $(/ \mu \mathrm{l})$} & $<350$ & 38 & 65.00 & 24 & 41.38 & 17 & 29.31 & 0.002 \\
\hline & $\geq \mathbf{3 5 0}$ & 20 & 35.00 & 34 & 58.62 & 41 & 70.69 & \\
\hline \multirow{2}{*}{ CV VIH (copies/ml) } & $<50$ & - & - & 50 & 86.21 & 52 & 89.66 & 0.004 \\
\hline & $\geq \mathbf{5 0}$ & - & - & 8 & 13.79 & 6 & 10.34 & \\
\hline \multirow{2}{*}{ ALAT (UI/I) } & $<40$ & 49 & 84.48 & 50 & 86.20 & 53 & 91.38 & 0.01 \\
\hline & $\geq \mathbf{4 0}$ & 9 & 15.52 & 8 & 14.80 & 5 & 8.62 & \\
\hline \multirow{2}{*}{ Creatinine (mg/l) } & $<13$ & 23 & 39.66 & - & - & 12 & 20.69 & \\
\hline & $\geq 13$ & 35 & 60.34 & - & - & 46 & 79.31 & 0.43 \\
\hline
\end{tabular}

Of the 58 patients enrolled, 2 died during their progression, (3.45\%) of lethality.

\section{Discussion}

Of the 457 B viral hepatitis tests performed in people living with HIV followed at CTA, from January $1^{\text {st }} 2010$ to December $31^{\text {st }} 2014,58$ were positive, $(\mathbf{1 2 . 7 \%})$ of HIV-HBV co-infection prevalence. This is obviously lower than the (16.8\%) prevalence found by H. Ndiaye-Diop et al. in Dakar in 2008 (Diop-Ndiaye et al., 2008), but similar to the prevalence found by Lô et al., in 2012 (Lô et al., 2012) (11\%) among pregnant women living with HIV in Senegal. This decrease in seroprevalence could be explained by the effectiveness of vaccination against viral hepatitis B in Senegal and the systematic search for HBsAg in the assessment at prenatal consultations.

However, this prevalence corroborates the current global co-infection HIV/HBV trend which is $5-15 \%$ worldwide (WHO, 2015).This is higher than those found in African sources. Tremeau-Bravard, A. et al. in Nigeria in 2012, Muriuki et al in Kenya in 2013, Kapembwa et al in Zambia in 2011 (Tremeau-Bravard, Ogbukagu, Ticao, \& Abubaka, 2012; Beatrice, Michael, Dorcas, Anthony, \& Samoel, 2013; Kapembwa et al., 2011), who found respectively $7,9 \% ; 6 \% ; 9.9 \%$. On the other hand, Lukhwareni et al. (Lukhwareni, Burnett, Selabe, Mzileni, \& Mphahlele, 2009) in South Africa in 2009, found a much higher prevalence than ours (22.9\%).

The average age of patients was $39.62 \pm 10.12$ [21 to 61]. This is higher than the average found in available sources: 34 years in the study of Chloe L. Thio et al. (Thio et al., 2013), 36 years in that of Attia et al. (Attia et al., 2012), 32 years in that realized by Yitayih M. et al. (Yitayih, Meseret, Fanaye, \& Yeshambel, 2013), 38 years in the work of H. Diop-Ndiaye et al. (Diop-Ndiaye et al., 2008). This could be explained by the youth of the overall African population but also by the fact that the population is sexually active at this age. 
In our series, there is a slight male predominance (51.17\%) with a sex ratio of 1.23.

The predominant character of men in PLHIV with HBV is generally confirmed by the review of the literature. Previous work on the same site showed that men were more concerned than women $\mathrm{p}=0.002$. (Diop-Ndiaye et al., 2008). Taiwo Modupe Balogun et al. reported that the prevalence of HIV-HBV co-infection was higher $(\mathrm{p}=0.001)$ in men (37.5\%) than in women (24.3\%) (Taiwo Modupe, Samuel, \& Emmanuel Folorunso, 2012). Given explanations reveal unprotected multipartnership sexual activities.

Of the 5639 HIV patients in the study of Jong Hun Kim et al. conducted in the USA, HBsAg seroprevalence was $4.47 \%$. Men were the majority $(80.6 \%)$. This confirms that the prevalence of HBV in PLHIV is high even in areas of low HBV prevalence (Bado et al., 2013).

Our results are different from those reported by most African authors who noted a female predominance. This is the case of Chloe L. Thio et al. in a multicentric study (Thio et al., 2013), G. Bado et al. in Burkina Faso (Kim, Psevdos, Suh, \& Sharp, 2008), Nimzing Gwamzhi Laped et al. in Nigeria (Ladep et al., 2013), Yitayih. et al. in Ethiopia (Yitayih, Meseret, Fanaye, \& Yeshambel, 2013) and Attia et al. in Cote d'Ivoire, (Attia et al., 2012).

Monogamous married patients were the most represented group (43.10\%), followed by unmarried patients (24.14\%).

Our results are similar to those reported by Yitayih W. et al. in 2013 in Ethiopia, 50\% and 18\% (Yitayih et al., 2013); Diombana in 2010 in Mali (Diombana, 2010) who had found $21.18 \%$ of unmaried and $19.53 \%$ married.

On the other hand, Walter et al. in 2007 in Italy (Walter \& Miele, 2007) found a remarkable predominance of unmaried $(51.50 \%)$. This difference is related to the fact that the study by Walter R. et al. focused on detainees who were predominantly young and unmarried.

In our series, fever and alteration of the general health conditions were the most visible symptoms with respectively (65.52\%) and (60.34\%). Ascites, hepatomegaly and jaundice were present in 19, 12 and 6 patients respectively. These results are similar to those found by Diombana S. in 2010 (Diombana, 2010).

More than half of the patients were included at stages III and II as per the WHO staging system, with (37.93\%) and (29.31\%) respectively.

Our results are similar to data from available sources, particularly those of DIOMBANA S. in Mali in 2010 (Diombana, 2010), ATTIA et al. in 2012 in Côte d'Ivoire (Attia et al., 2012) which found 20.28\% and 19.87\%; 47.5\% and $35 \%$ respectively.

This is due to the fact that patients come to the hospital only at an advanced stage of the disease when symptoms of opportunistic infections appear.

In our series, $24.14 \%$ of patients were undernourished (BMI $\left.<18.5 \mathrm{~kg} / \mathrm{m}^{2}\right), 15.52 \%$ overweight and $3.45 \%$ obese. John R. et al. in Rwanda in 2013 (Rusine et al., 2013) found 9.8\% undernourished, 32.9\% overweight and obese.

Of the 58 patients co-infected with HIV-HBV, $79.31 \%$ were on first-line ART containing Tenofovir/lamivudine or Tenofovir/Emtricitabine active for both viruses.

Diombana in Mali in 2010 (Diombana, 2010) 5.36\% were actively treated on both viruses.

These contradictory results could be explained by the fact that since 2006, any patient in Senegal with an HIV-HBV co infection is treated with TDF and 3TC or FTC.This is in accordance with the WHO recommendations. As a result, our patients who were not under this regimen were put on 2nd line treatment.

The median CD4 lymphocyte at baseline was 235 cells/all [3-936]. Sixty-five percent of patients had severe immunosuppression ( $<350$ cells/all). This median of CD4 is similar to that of John. et al. in Rwanda (Rusine et al., 2013) who found a median of 222 cells/all [142-289]); Higher than that of Van Greisen J. et al. in Cambodia 104 cells/all [26-227]) in 2013 (van Griensven, Phirum, Choun, Thai, De Weggheleire, \& Lynen, 2014) but lower than that of Attia., In Ivory Coast in 2012 (Attia et al., 2012) who had a median of 341/].

The median HIV viral load at inclusion was 4.1 log copies/ml [3.89-5.12]. Our results are similar to those of John. et al. in Rwanda (Rusine et al., 2013) and Attia et al. in Cote d'Ivoire in 2012 (Attia et al., 2012) who had noted 4.81log copies $/ \mathrm{ml}$ [4.22-5.33] and 4.87log copies/ $\mathrm{ml}$ respectively [4.15-5.45].

The average transaminase (ALT) was $27.22 \pm 25.11 \mathrm{IU} / 1$ at inclusion. ALT was elevated in $13.52 \%$ of cases. Attia et al. in Cote d'Ivoire in 2012 (Attia et al., 2012), and Van Griensven et al. in Cambodia found lower than ours in 2013 (van Griensven et al., 2014), with respectively, 8.6\% and 3.9\% respectively. 


\section{Conclusion}

The seroprevalence of viral hepatitis B remains relatively high (12.70\%) among PLHIV in Dakar. Management of hepatitis B is a challenge due to the lack of public awarness of common symptoms. A low lethality of $3.45 \%$ in our patients is noted. Given the results of this descriptive work, it is necessary to conduct a multicenter, in-depth analytical study to better assess not only the profile of HIV-HBV co-infected but also the impact of antiretroviral therapy on the evolution of HBV disease.

\section{Authors' Contributions}

NGOM GUEYE Ndeye Fatou, Mahamat Bolti, Cheikh tidiane Ndour: design, data collection, statistical analysis and manuscript review. Other authors: design and manuscript review. All the authors have read and approved the final version of the manuscript.

\section{Acknowledgements}

We thank all the patients and staff who participated in the study.

\section{Competing Interests Statement}

The authors declare that there is no conflict of interests regarding the publication of this paper.

\section{References}

Attia K. A., Eholié S., Messou E., Danel C., Polonceau S., Chenal H. et al. (2012). Hepatitis B and HIV Co-Infection. World J. Hepatol., 4(7), 218-223. https://doi.org/10.4254/wjh.v4.i7.218

Attia, K. A. (2007). Co-infection VIH-VHB au sud du Sahara: données épidémiologiques, cliniques et thérapeutiques. J Afr. Hepato Gastroenterol, 1, 51-53. https://doi.org/10.1007/s12157-007-0011-z

Bado, G., Penot, P., N'Diaye, M. D., Amiel, C., Hema, A., Kamboulé, E. B., Guiard-Schmid, J. B., Kaboré, N. F. et al. (2013). Hepatitis B seroprevalence in HIV-infected patients consulting in a public day care unit in Bobo Dioulasso, Burkina Faso. Med Mal Infect., 43(5), 202-207.

Beatrice, M. M., Michael, M. G., Dorcas, W., Anthony, K. N., \& Samoel, A. K. (2013). Prevalence of hepatitis B and $\mathrm{C}$ viral co-infections among HIV-1 infected individuals in Nairobi, Kenya. BMC Research Notes, 6, 363. https://doi.org/10.1186/1756-0500-6-363

Diombana, S. (2010). Epidémiologie de la co-infection VIH/VHB à l'hôpital de Sikasso et au centre de référence kenedougou solidarité. Thèse de doctorat en médecine, Bamako, 60p.

Diop-Ndiaye, H., Touré-Kane, C., Etard, J. F., Lô, G., Diaw, P., Ngom-Gueye, N. F. et al. (2008). Hepatitis B, C seroprevalence and delta viruses in HIV-1 Senegalese patients at HAART initiation (retrospective study). Med Virol., 80(8), 1332-6. https://doi.org/10.1002/jmv.21236

James, F., Lai, C.-H., Seta, W.-K., \& Yuen, M. F. (2011). Nucleoside/nucleotide analogues in the treatment of chronic hepatitis B. J. Antimicrob. Chemother, 66(12), 2715-2725. https://doi.org/10.1093/jac/dkr388

Joshi, D., O'Grady, J., Dieterich, D., Gazzard, B., \& Agarwal, K. (2011). Increasing burden of liver disease in patients with HIV infection. Lancet, 377, 1198-1209. https://doi.org/10.1016/S0140-6736(10)62001-6

Kapembwa, K. C., Goldman, J. D., Lakhi, S., Banda, Y., Bowa, K., Vermund, S. H., ... Chi, B. H. (2011). HIV, hepatitis $B$, and hepatitis $C$ in Zambia. $J$ Global Infect Dis, 3, 269-274. https://doi.org/10.4103/0974-777X.83534

Kim, J. H., Psevdos, G., Suh, J., \& Sharp, V. L. (2008). Co-infection of hepatitis B and hepatitis C virus in human immunodeficiency virus-infected patients in New York City, United States. World J Gastroenterol, 14(43), 6689-6693. https://doi.org/10.3748/wjg.14.6689

Ladep, N. G., Agaba, P. A., Agbaji, O., Muazu, A., Ugoagwu, P., Imade, G., ... \& Kanki, P. (2013). Rates and impact of hepatitis on human immunodeficiency virus infection in a large African cohort. World Journal Gastroenterol., 19(10), 1602-1610. https://doi.org/10.3748/wjg.v19.i10.1602

Lô, G., Diawara, P. S., Diouf, N. N., Faye, B., Seck, M. C., Sow, K. et al. (2012). Prévalence de l'antigène de surface du virus de l'hépatite B (AgHBs) chez les femmes enceintes au laboratoire de l'Hôpital Militaire de Ouakam (HMO). Dakar. Médecine d'Afrique Noire, 59(5), 241-244.

Lukhwareni, A., Burnett, R. J., Selabe, S. G., Mzileni, M. O., \& Mphahlele, M. J. (2009). Increased detection of HBV DNA in HBsAg-positive and HBsAg-negative South African HIV/AIDS patients enrolling for highly active antiretroviral therapy at a Tertiary Hospital. $J$ Med Virol, 81, 406-412. 
https://doi.org/10.1002/jmv.21418

Mehdi, Z. (2013). Occult Hepatitis B: Clinical Viewpoint and Management. Hepatitis Research and Treatment, Article ID 259148.

Mehdi, Z., Sakineh, E., Mohammad, F., Mansour, R., \& Alireza, A. (2012). Celiac Disease: Serologic Prevalence in Patients with Irritable Bowel Syndrome. J. Res. Med. Sci., 17(9), 839-42.

Miailhes, P, Maynard-Muet, M., Carrat, F., Lascoux-Combe, C., Rey, D., Sogni, P., et al. (2013). Additional pegylated interferon in HBe Ag positive HIV co-infected patients on cART including tenofovir: the ANRS HB01 EMVIPEG study. In: 20th Conference on Retroviruses and Opportunistic Infections. Atlanta, USA; 2013 (abstract 669). (Miailhes et al., 2013)

OMS. (2013). Rapport ONUSIDA sur l'épidémie mondiale du VIH/sida 2013.

Raimondo, G., Caccamo, G., Filomia, R., \& Pollicino, T. (2013). Occult HBV Infection. Seminars in Immunopathology, 35(1), 39-52. https://doi.org/10.1007/s00281-012-0327-7

Rusine, J., Ondoa, P., Asiimwe-Kateera, B., Boer, K. R., Uwimana, J. M., Mukabayire, O., ... \& van de Wijgert, J. H. (2013). High seroprevalence of HBV and HCV infection in HIV-infected adults in Kigali, Rwanda. PloS one, 8(5), e63303. https://doi.org/10.1371/journal.pone.0063303

Taiwo Modupe, B., Samuel, E., \& Emmanuel Folorunso, O. (2012). HIV, Hepatitis B and C viruses' coinfection among patients in a Nigerian tertiary hospital. Pan African Medical J., 12, 100.

Thio C.L., Laura, S., Melissa, S., Hyon, H., Shanmugam, S. et al. Currier Characterization of HIV-HBV Coinfection in a Multinational HIV-Infected Cohort. AIDS, 27, 191-201. https://doi.org/10.1097/QAD.0b013e32835a9984

Tremeau-Bravard, A., Ogbukagu, I. C., Ticao, C. J., \& Abubaka, J. J. (2012). Seroprevalence of hepatitis B and C infection among the HIV-positive population in Abuja, Nigeria. Afr Health Sci., 12(3), 312-317. (Tremeau-Bravard, Ogbukagu, Ticao, \& Abubaka, 2012)

van Griensven, J., Phirum, L., Choun, K., Thai, S., De Weggheleire, A., \& Lynen, L. (2014). Hepatitis B and C co-infection among HIV-infected adults while on antiretroviral treatment: long-term survival, CD4 cell count recovery and antiretroviral toxicity in Cambodia. PloS one, 9(2), e88552. https://doi.org/10.1371/journal.pone.0088552

Walter, R., \& Miele, L. (2007).Les déterminants sociodémographiques des co-infections par l'hépatite B et le virus de l'hépatite $\mathrm{C}$ chez les détenus centrale italienne. BMC infectious diseases, 7(100), 13-16.

Yitayih, W., Meseret, A., Fanaye, A., \& Yeshambel, B. (2013). HBV and HCV seroprevalence and their correlation with CD4 cells and liver enzymes among HIV positive individuals at University of Gondar Teaching Hospital, Northwest Ethiopia. Virol J., 10, 171. https://doi.org/10.1186/1743-422X-10-171

\section{Copyrights}

Copyright for this article is retained by the author(s), with first publication rights granted to the journal.

This is an open-access article distributed under the terms and conditions of the Creative Commons Attribution license (http://creativecommons.org/licenses/by/4.0/). 